\title{
Impact of Geriatric Hotlines on Health Care Pathways and Health Status in Patients Aged 75 Years and Older: Protocol for a French Multicenter Observational Study
}

Laure Martinez ${ }^{1 *}, \mathrm{MD}$; Noémie Lacour ${ }^{2 *}, \mathrm{MD}$; Régis Gonthier ${ }^{1^{*}}, \mathrm{MD}, \mathrm{PhD}$; Marc Bonnefoy ${ }^{3 *}, \mathrm{MD}, \mathrm{PhD}$; Luc Goethals $^{4,5^{*}}$, MSc; Cedric Annweiler ${ }^{6,78^{*}}, \mathrm{MD}$, PhD; Nathalie Salles ${ }^{9 *}, \mathrm{MD}$, PhD; Nathalie Jomard ${ }^{3 *}$, MD; Jérôme Bohatier $^{10^{* *}}, \mathrm{MD}$; Magali Tardy ${ }^{11^{*}}, \mathrm{MD}$; Etienne Ojardias ${ }^{1 *}, \mathrm{MD}$; Romain Jugand ${ }^{1^{*}}, \mathrm{MD}$; Bienvenu Bongué ${ }^{4,5,12^{*}}, \mathrm{PhD}$; Thomas Celarier ${ }^{1,4,13^{*}}$, MD

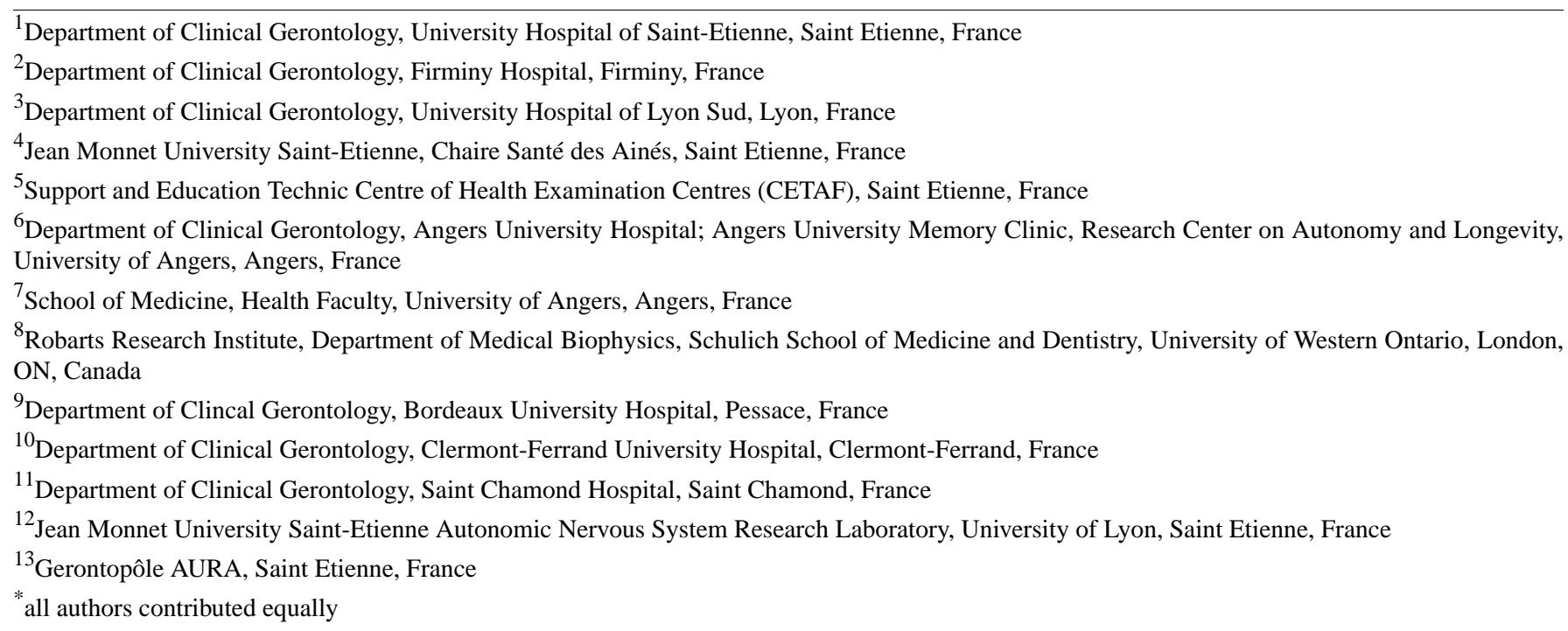

\section{Corresponding Author:}

Laure Martinez, MD

Department of Clinical Gerontology, University Hospital of Saint-Etienne

44 rue Pointe Cadet

Saint Etienne, 42055 Cedex 2

France

Phone: 33477127117

Email: laure.martinez@chu-st-etienne.fr

\section{Abstract}

Background: In France, emergency departments (EDs) are the fastest and most common means for general practitioners (GPs) to cope with the complex issues presented by elderly patients with multiple conditions. EDs are overburdened, and studies show that being treated in EDs can have a damaging effect on the health of elderly patients. Outpatient care or planned hospitalizations are possible solutions if appropriate geriatric medical advice is provided. In 2013, France's regional health authorities proposed creating direct telephone helplines, "geriatric hotlines," staffed by geriatric specialists to encourage interactions between GP clinics and hospitals. These hotlines are designed to improve health care pathways and the health status of the elderly.

Objective: This study aims to describe the health care pathways and health status of patients aged 75 years and older hospitalized in short-stay geriatric wards following referral from a geriatric hotline.

Methods: The study will be conducted over 24 months in seven French university hospital centers. It will include all patients aged 75 and older, living in their own homes or nursing homes, who are admitted to short-stay geriatric wards following hotline consultation. Two questionnaires will be filled out by medical staff at specific time points: (1) after conducting the telephone consultation and (2) on admitting the patient to a short-stay geriatric medical care. The primary endpoint will be mean hospitalization 
duration. The secondary endpoints will be intrahospital mortality rate, the characteristics of patients admitted via the hotline, and the types of questions asked and responses given via the hotline.

Results: The study was funded by the National School for Social Security Loire department (École Nationale Supérieure de Sécurité Sociale) and the Conference for funders of prevention of autonomy loss for the elderly of the Loire department in November 2017. Institutional review board approval was obtained in April 2018. Data collection started in May 2018; the planned end date for data collection is May 2020. Data analysis will take place in the summer of 2020, and the first results are expected to be published in late 2020 .

Conclusions: The results will reveal whether geriatric hotlines provide the most effective management of elderly patients, as indicated by shorter mean hospitalization durations. Shorter hospital durations could lead to a reduced risk of complications - geriatric syndromes - and the domino chain of geriatric conditions that follow. We will also describe different geriatric hotlines from different cities and compare how they function to improve the health care of the elderly and pave the way toward new advances, especially in the organization of the care path.

Trial Registration: ClinicalTrials.gov NCT03959475; https://clinicaltrials.gov/ct2/show/NCT03959475

International Registered Report Identifier (IRRID)： DERR1-10.2196/15423

(JMIR Res Protoc 2020;9(2):e15423) doi: 10.2196/15423

\section{KEYWORDS}

aged; health care; hotline; emergency department; general practice medicine

\section{Introduction}

The world's populations are aging, which represents a serious public health issue. There are many consequences categorized into four main types: (1) demographic, with increasing numbers and proportions of people older than 65 years with increased life expectancy; (2) epidemiologic, with an accumulation of chronic diseases, incapacitating conditions, and disabilities; (3) economic, with increased health costs and accelerated health care reforms; and (4) social.

The organizational model of hospitals is one of the first elements to be affected by population aging. Over time, the elderly will become the central focus of all hospitals. But how will these establishments address this issue? In France, emergency departments (EDs) are the fastest and most common means for general practitioners (GPs) to cope with the complex issues presented by elderly patients with multiple conditions $[1,2]$. These services are already overwhelmed, and studies show that being treated in EDs can have a damaging effect on the health of elderly patients [3]. These emergency services can be traumatizing for the elderly and cause the many different complications that are commonly grouped together as "geriatric syndromes" [4-10]. When treated in EDs, the elderly are at higher risk of functional decline due to falls, drug iatrogenesis, and incontinence [11-13].

For emergency physicians, treating elderly patients with multiple pathologies, who often arrive alone, proves to be challenging. Treatment is rendered even more difficult by the lack of time emergency physicians have at their disposal due to EDs being more and more overburdened.

Studies have reported that in $20 \%$ to $35 \%$ of cases, there was no real need for admission to EDs, and outpatient care or planned hospitalizations would have been possible if appropriate geriatric care was available [14]. Therefore, nearly a quarter of these hospitalizations could have been anticipated and prevented. Some studies on hospitalization durations report that patients

with initially planned hospitalizations seem to experience longer times being seen and treated in EDs. Furthermore, this significant number of hospitalizations creates financial issues. According to the French High Council for the Future of Health Insurance, an estimated $€ 2$ billion are lost due to the segmentation and inadequacy of response, along with unnecessary hospitalizations [15]. Overall, the literature highlights the need to better coordinate outpatient care with hospital services to provide the elderly with access to more effective care [16].

To improve interactions between GP clinics and hospitals, France's regional health authorities first organized the area as a unit focused on hospital centers incorporating both EDs and short-stay geriatric wards enabling immediate admission. In parallel, the regional health authorities created telephone hotlines designed to enhance GP clinic-hospital interactions with the aim of reducing the number of hospitalizations, particularly by improving the quality of response. The desired outcome was to improve both the care pathways and health status of the elderly. This hotline service was a recent creation (2013) and is still in an experimental form and not yet widespread. Its use still varies widely across the country, and we have yet to gauge its real value.

The primary objective of this study is to describe the health care pathways and status of patients aged 75 years and older hospitalized in short-stay geriatric care and referred via the hotline. The study population will be from different geriatric care hotlines from around France.

The aims of this study are to describe and compare how the geriatric medicine hotlines function with the goal of standardizing their use and defining ways they can be improved. We will also analyze the principal responses provided to GPs who call the hotlines and improve awareness of this tool. We hypothesize that geriatric hotlines will lead to reduced mean durations of hospitalizations by helping prevent time spent in EDs when it is unnecessary and potentially a risk. Through the use of a direct geriatric hotline diagnostic tool, we believe 
elderly patients will experience better health care pathways that no longer involve multiple trips to EDs. The hotlines may facilitate better adapted and more appropriate responses to situations that do not necessarily need hospitalization and provide better alternatives (eg, therapeutic medical and social care, outpatient care, consultations, ambulance services, telemedicine).

\section{Methods}

\section{Design and Setting}

This will be a multicenter descriptive study conducted in seven French investigating centers (including university centers, across three different regions) with subgroup analysis (Table 1). Participating establishments will all be voluntary. To participate in the study, the center must have a specific and separate telephone line for doctor-doctor communications. Only calls originating from health care professionals will be included. The study will last for 24 months (May 2018 to May 2020). The course of the study and its design are presented in Figure 1.

Two questionnaires will be distributed at two distinct time points: after telephone consultation (hotline) and after admission to a short-stay geriatric ward. The first questionnaire will be filled out via the hotline by the geriatric specialist answering the call. A second questionnaire will then be filled out during the patient's hospitalization by the treating geriatric specialist.

Table 1. Description of geriatric care offered by different participating centers.

\begin{tabular}{|c|c|c|c|c|c|c|c|c|c|}
\hline $\begin{array}{l}\text { Paticipating } \\
\text { center }\end{array}$ & $\begin{array}{l}\text { Residents, } \\
\mathrm{n}\end{array}$ & $\begin{array}{l}\text { Hospital } \\
\text { beds, } n\end{array}$ & $\begin{array}{l}\text { Short-stay } \\
\text { geriatric care }\end{array}$ & $\begin{array}{l}\text { Postdischarge } \\
\text { care }\end{array}$ & $\begin{array}{l}\text { Long-term reha- } \\
\text { bilitation care }\end{array}$ & Consultation & $\begin{array}{l}\text { Outpatient } \\
\text { clinic }\end{array}$ & $\begin{array}{l}\text { Ambulance } \\
\text { care }\end{array}$ & $\begin{array}{l}\text { Telemedical } \\
\text { consultation }\end{array}$ \\
\hline Bordeaux & 252,000 & 3076 & $\mathrm{x}$ & $\mathrm{x}$ & $\mathrm{x}$ & $\mathrm{x}$ & $\mathrm{x}$ & $\mathrm{x}$ & $\mathrm{x}$ \\
\hline $\begin{array}{l}\text { Clermont- } \\
\text { Ferrand }\end{array}$ & 141,400 & 2136 & $\mathrm{x}$ & $\mathrm{x}$ & $\mathrm{x}$ & $\mathrm{x}$ & $\mathrm{x}$ & & \\
\hline Saint & 171,100 & 1819 & $\mathrm{x}$ & $\mathrm{x}$ & $\mathrm{x}$ & $\mathrm{x}$ & $\mathrm{x}$ & $\mathrm{x}$ & $\mathrm{x}$ \\
\hline \multicolumn{10}{|l|}{ Etienne } \\
\hline Angers & 151,500 & 1445 & $\mathrm{x}$ & $\mathrm{x}$ & $-^{a}$ & $\mathrm{x}$ & $\mathrm{x}$ & $\mathrm{x}$ & $\mathrm{x}$ \\
\hline Lyon Sud & 513,300 & 1038 & $\mathrm{x}$ & $\mathrm{x}$ & $\mathrm{x}$ & $\mathrm{x}$ & $\mathrm{x}$ & $\mathrm{x}$ & - \\
\hline Saint & 34,870 & 710 & $\mathrm{x}$ & $\mathrm{x}$ & - & $\mathrm{x}$ & - & $\mathrm{x}$ & - \\
\hline \multicolumn{10}{|l|}{ Chamond } \\
\hline Firminy & 16,840 & 475 & $\mathrm{x}$ & $\mathrm{x}$ & $\mathrm{x}$ & $\mathrm{x}$ & $\mathrm{x}$ & $\mathrm{x}$ & - \\
\hline
\end{tabular}

${ }^{\mathrm{a}}$ Service not offered. 
Figure 1. Flowchart of the study protocol.
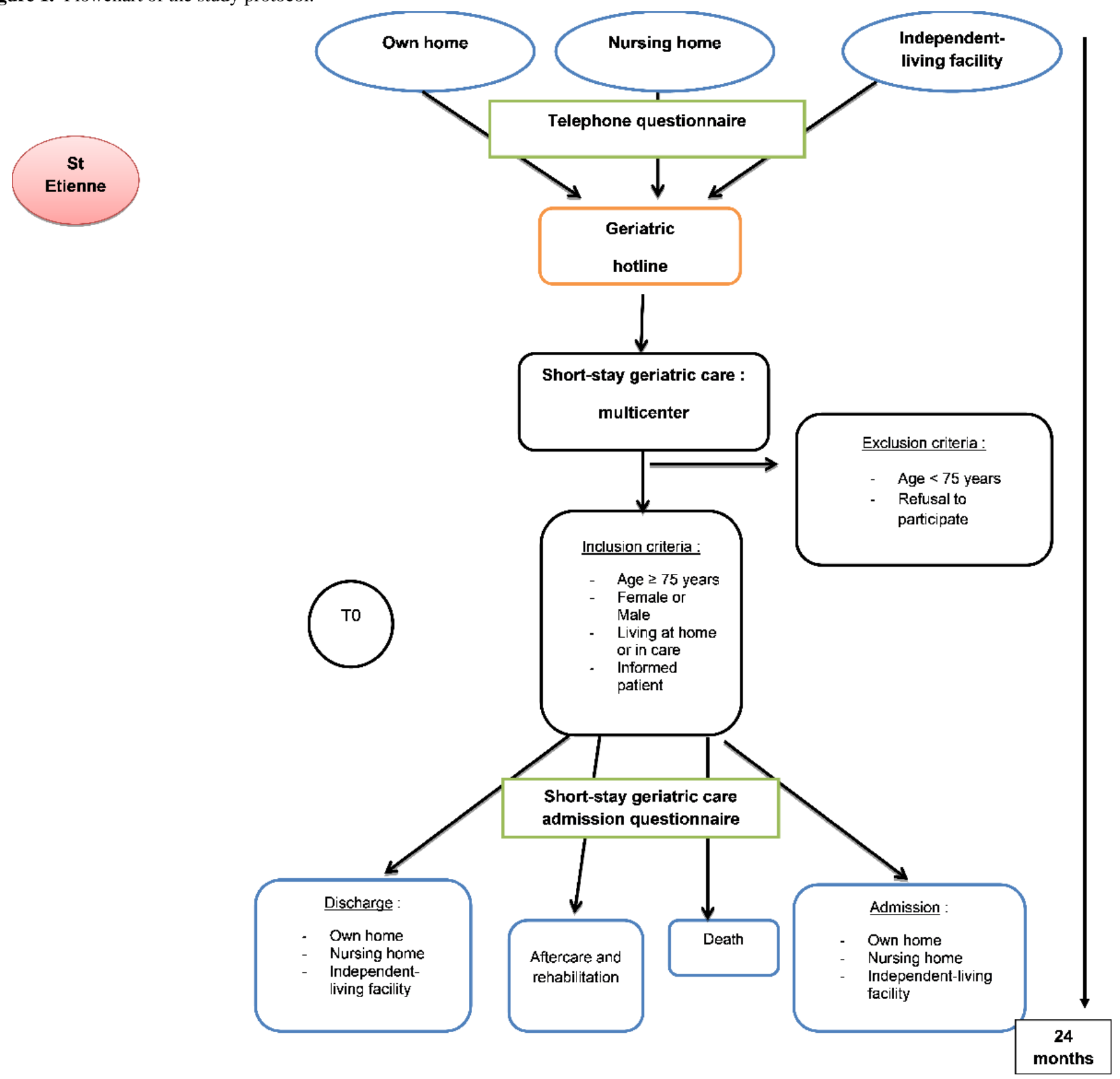

\section{Participants}

The study population will be people aged 75 years and older, living in their own home or a care facility (including independent-living facilities), hospitalized in short-stay geriatric care and referred by the hotline in one of the investigating centers. All participants will be fully aware of the study and their rights regarding their participation. All participating patients will give their consent. Participants or a legally authorized representative will receive informational brochures and give their informed oral consent (more visual difficulties and writing for the elderly). All participants will be able, at any moment and by any method, to withdraw from the study.

\section{Inclusion Procedure}

When the patient is admitted to short-stay geriatric care, the investigators in each hospital of the study will first check the inclusion and noninclusion criteria of the patient. Then, they will explain the study to the patient and give the patient an information form. This will all be the responsibility of each center independently.

\section{Selection and Exclusion of Participants From Study}

The inclusion criteria will be patients aged 75 years and older, male or female, living in their own home or a care facility (including independent-living facilities), hospitalized in short-stay geriatric care, and with confirmed receipt of information on the study and their rights, as stipulated by articles L.1122-1 of the French public health code, by 57 of the "Informatique et Libertés" data protection act, and by MR-003 of the French data protection and civil liberties authority (CNIL). The exclusion criteria will be patients aged younger than 75 years or refusing to participate.

\section{Monitoring}

This study will involve no extra examinations or treatment besides traditional practices. The only difference will be the digitization of all medical findings for analysis. Data will be 
kept confidential and anonymized for analyses. This study will be noninterventional. All interventions will be carried out following normal clinical practices. There will be no unusual risk or specific constraint for participating patients.

\section{Study Endpoint}

The study endpoint will correspond to when the patient is discharged from short-stay geriatric care. The duration of study participation for each patient will be the duration of their short-stay geriatric care.

\section{Evaluation Criteria}

The primary endpoint is the mean duration of hospitalization in short-stay geriatric care. The secondary endpoints are hospital mortality rate, assessment of health status of elderly patients hospitalized in short-stay geriatric wards using different criteria and their outcomes following discharge, describing and comparing how the different hotlines across France function, analyzing the principal responses provided to doctors using the hotline, and improving awareness.

\section{Recorded Variables and Source Data}

The study data will be collected directly from the questionnaires as the study progresses. For the first questionnaire (context of calls and solutions proposed), filled out by the hotline geriatric specialist (Textbox 1), health and administrative information will be collected for the study. The health data collected will include the identification of both speakers on the call, patient age, reasons for calling, degree of emergency as perceived by the geriatric specialist and the calling doctor (evaluated by simple scale from 0 to $10 ; 0$ being a null degree of urgency and 10 an absolute urgency), and the responses offered by the geriatric specialist. The administrative data will include call duration (in minutes).

This questionnaire will be anonymous with no identifying criteria. It will be filled out every time contact is made via the hotline, irrespective of what responses are offered by the doctor (referrals to short-stay geriatric care or not).

For the second questionnaire, filled out by the geriatric specialist treating the patient during their hospitalization in short-stay geriatric care following referral from the hotline (Textbox 2), the sociodemographic, health, family, living situation, and location information will be collected for the study.

Sociodemographic data will include the first and last name of the patient, Patient Permanent Identification number, and patient age. These data will be anonymized on entry.

The health data collected will be the reason for hospitalization; number of hospitalizations during the past year; polypharmacy (four or more medications at the same time); biological data [17], including albumin and C-reactive protein levels for assessing nutritional status; and Charlson Comorbidity Index calculation using patient history for assessing the comorbidities of our geriatric population [18-20]; evaluation of activities of daily living (ADL) before hospitalization according to the validated ADL (/6) [21] and instrumental ADL scales (/4) [22]; evaluation of cognitive status using the Mini-Mental State Examination score (/30) [23]; and recommended referral after hospital discharge.

We chose the Charlson Comorbidity Index because it is a validated, reproducible, and simple comorbidity score that measures the impact of age (as there is excess mortality according to age), weighting by age from 1 (50-59 years) to 5 (90-99 years). This score is widely used for geriatrics publications.

Family or marital status data will include single or with a partner, and with or without children. The living situation data will be the residence of the patient (own home, independent-living facility, nursing home). Type of living area will be urban, semiurban, or rural. 
Textbox 1. Context of calls and solutions proposed.

\section{Caller}

- General practitioner

- Hospital physician

- Other

Hotline responding doctor

- Assistant physician

- Hospital practitioner

Reason for calling

- Advice

- Emergency department hospitalization

- Emergency geriatric department hospitalization

- Consultation request

- Deferred hospitalization

Patient age (years), mean (SD)

Degree of emergency perceived by the hotline doctor, mean (SD)

Degree of emergency perceived by the calling doctor, mean (SD)

Response

- Simple advice

- Medical

- Social-medical

- Therapeutic

- Emergency admission

- To emergency department:

- $\quad$ No beds in short-stay geriatrics

- $\quad$ Emergency care required

- Short-stay geriatric care: allocated bed

- Yes

- No

- $\quad$ Deferred hospitalization (days), mean (SD)

- Nonhospital ambulance services

- Outpatient care

- Consultation

- Teleconsultation

- Temporary nursing home

Call duration (minutes), mean (SD) 
Textbox 2. Sociodemographic participant characteristics.

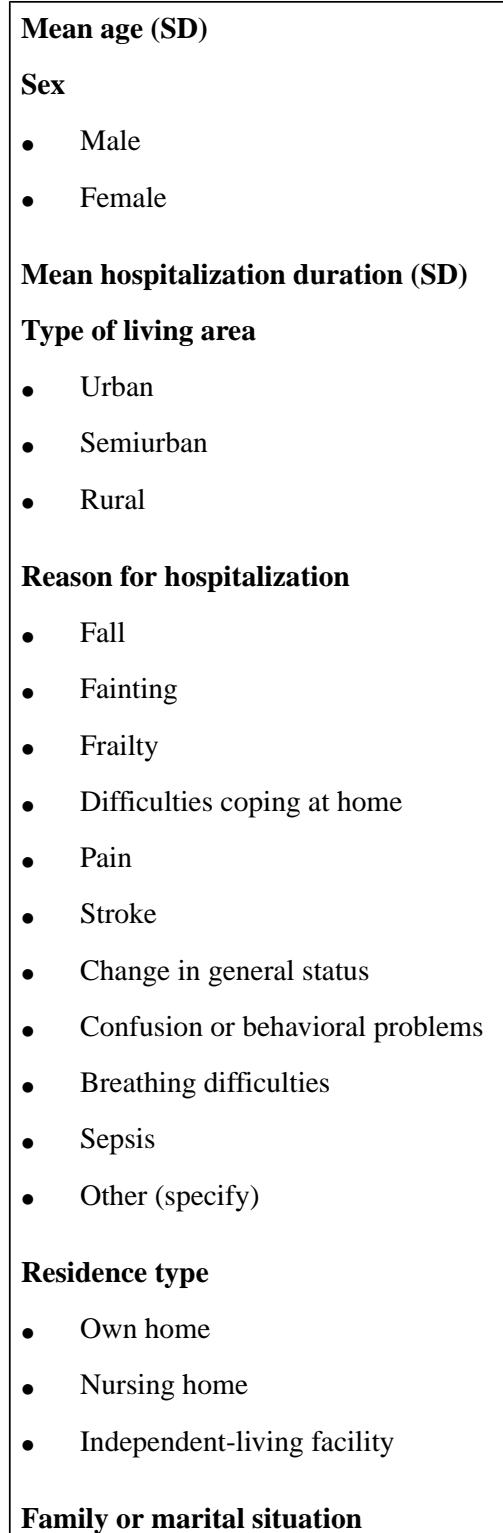

- With a partner

- Alone no children

- Alone with children

- Other

Polypharmacy (>4)

- Yes

- $\quad$ No

Charlson Comorbidity Index score, mean (SD)

Previous autonomy

- Mean activities of daily living (SD)

- Mean instrumental activities of daily living (SD)

- Mean blood albumin (SD)

- $\quad$ Mean C-reactive protein (SD)

Cognitive disorder 
- $\quad$ Mean Mini-Mental State Examination score (SD)

- Diagnosed dementia

Walking difficulties

- Walking aids

- History of falls

Outcomes

- $\quad$ Return home

- Return to nursing home

- Long-term rehabilitation

- Follow-up care then nursing home

- Admission to nursing home

- Admission to independent-living facility

- Death

- $\quad$ Return home with planned help (specify)

\section{Statistical Analysis}

This is a pilot study. Given the need for subgroup analyses and information concerning the activities conducted at the investigating centers participating in this study, approximately 250 patients are required per center (ie, 2000 in total). This goal is attainable in 24 months, which represents the entire duration of the study. Statistical analysis will be done by statisticians. Different measures will be used depending on the desired descriptive statistics. All analyses will be conducted on the entire included population and each investigating center.

Univariate analysis, descriptive analyses of the study population, will involve recorded variables, comparison of subjects included via the hotline according to sex, and type of discharge using parametric or nonparametric tests and according to the distribution of variables (chi-square tests for quantitative variables, Student $t$ tests for qualitative variables, test significance set at $5 \%$ ).

Multivariate analyses will include analyses of mean values (ANOVA), the use of a generalized linear model, the use of a mixed model for taking into account the random effect of choosing seven centers. A multiple-component analysis will be used to identify different patient groups (patient profile analysis).

\section{Results}

The study was funded and peer reviewed by the National School for Social Security Loire department (École Nationale Supérieure de Sécurité Sociale) and the Conference for funders of prevention of autonomy loss for the elderly of the Loire department in November 2017, and obtained institutional review board approval in April 2018 by the committee for the protection of persons of Sud Est V of Grenoble University Hospital Center (registered under 18-CETA-01 No.ID RCB 2018-A00609-46). Data collection started in May 2018. The planned end date for data collection is May 2020. Data analysis will take place in the summer of 2020. First results are expected to be published in late 2020 .

\section{Discussion}

This study will enable us to determine whether a geriatric hotline offers effective management of elderly patients. Could planned hospitalizations be the best solution for our elderly? Will this approach lead to less geriatric syndromes [4-10]?

Wargon et al [4] demonstrated that the elderly spend more time in EDs, which is a potential source of dysfunction in the organization care offered by these services and lowers chances of positive outcomes for the patient. Therefore, there is interest in enabling the assessment of geriatric health status to limit visits to EDs as much as possible and improve the care pathways offered to elderly patients. In a retrospective study, Mazière et al [8] demonstrated that elderly admissions to EDs are independently associated with functional decline in terms of daily activities. The findings of these studies indicate that improving interactions between GP care and hospital services could enable more direct referrals of patients to multidisciplinary care in short-stay geriatric wards, consequently improving the functional prognosis of elderly patients and avoiding geriatric syndromes secondary to ED care.

The study has several strengths. It is a multicentric study covering a large patient sample. The diversity of the participating investigating centers (across three different regions) and their populations is also likely to offer diverse responses. Is the time spent in ED consultations greater in the larger centers? Does this lead to more cases of geriatric syndrome? Are there closer, more effective ties between GP clinics and hospitals in areas with a lower population density? Do these areas (with a lower population density) benefit from better understanding and communication of this type of care? The analysis will be conducted across subgroups (town by town) to avoid confusion bias. The overall population will be sourced from different types of regions (ie, rural, semiurban, urban) to 
reveal whether this factor has an impact on the knowledge of or access to the hotline [24]. The analysis will enable evaluation of GP clinic-hospital interactions [25] according to population centers, and the need for links between these health care areas, to determine the strengths and limitations and to reinforce GP clinic and hospital collaboration with the aim of reducing ED admissions [26].

By analyzing center by center, we will be able to describe each center with the different responses they offer. Ideally, this will help to improve the function of the geriatric hotline for the entire country and pave the way to new advances, especially in the organization of the care path in the long run.

The analysis also will be conducted in two sections. First, the call to the hotline will be analyzed. Did the experience of the doctor responding to the call influence the type of care recommended and the response offered? Does a high level of perceived emergency correlate to hospitalization via the ED? Is the hotline solely used by general medicine doctors? Would it be a good idea to roll out access to the hotline to other hospital specialties? Given the growing issue of population aging, the current geriatric services are not enough to care for all the elderly. This is why specialists are turning more toward other fields for geriatric assessment (eg, oncology, orthopedics). This study will reveal the different responses that can be provided by this tool (the hotline), from therapeutic or medical advice to referrals for hospitalization, ambulance call-outs, consultations, telemedicine, and more.

Second, we will study the profile of patients referred for hospitalization via the hotline to determine the characteristics of those the hotline recommends for admission to improve their health care approach. Does this tool lead to direct hospitalization in short-stay geriatric care for the less-fragile patients who still have some autonomy? Are the motives for admission less serious? We hypothesize that the mean duration of hospitalization will be shorter in cases in which it is planned, which leads to the question of whether the future of hospitalization is influenced by the ways patients are admitted.
In their study involving 520 patients, Dijon et al [27] demonstrated that the intrahospital care pathways of geriatric patients referred directly to short-stay geriatric care are shorter and more effective than those experienced by patients who first went through EDs, with significantly shorter mean hospitalizations achieved through direct hotline-referred admissions (11.6 days versus 14.1 days with ED consultation; $P<.05)$. Patients admitted to short-stay care via EDs were also the quickest to be rehospitalized in the future.

Another advantage of our study is its innovative character because there are currently very few studies analyzing geriatric hotlines [25]. In addition, it is observational in nature, which enables many types of procedures from across the country to be analyzed, leading to more standardized approaches.

The study does have limitations, notably its nonrandomized nature. There is no comparison because it is a descriptive study. The quality of the responses will be operator-dependent. Eventually, the goal will be to conduct a second study aiming to compare profiles of elderly patients hospitalized in short-stay geriatric wards via EDs versus those referred via a geriatric hotline. Through the first questionnaire, we will analyze the different responses provided by the hotline (eg, call-outs, consultations, telemedicine, day hospital). We will evaluate the number of hospitalizations avoided or deferred in time following the use of the hotline to reduce inappropriate passage through EDs.

This first study will demonstrate if managing patients by means of a geriatric hotline offers the most effective approach and results in shorter mean hospitalization durations and thus fewer complications and geriatric syndromes and fewer trips to EDs. It will also describe and compare the function of different geriatric hotlines across France to improve health care pathways for the elderly and pave the way toward future advances, such as new modalities of patient management, the development of more appropriate responses to this population, and the reduction of inappropriate visits to emergencies, which we know can be deleterious for the elderly.

\section{Acknowledgments}

The study is funded by the National School for Social Security (En3s in French) and the Conference for funders of prevention of autonomy loss for the elderly of the Loire department (November 2017). Funding institutions will not interfere in any part of the study.

We would like to thank Norbert Deville (Directeur General of CETAF), Dominique Libault (Directeur de l'EN3S), Christophe Beaudouin (Directeur adjoint of EN3S), Michaël Galy (Directeur Général of St-Etienne University Hospital Center), and Prof Fréderic Roche for their help in implementing this project. We are also grateful to Prof Régis Gonthier for his contribution to the study design, and all the doctors and staff of the different participating centers, without whom this study could never take place.

\section{Authors' Contributions}

The chief investigator of the study, RG, as well as LM, NL, MB, TC, LG, CA, NS, NJ, JM, MT, EO, RJ, and BB were responsible for determining the research question, the design, methodology, and follow-up of the study; obtaining ethics approval; acquiring financial support; and writing the paper. BB and LG contributed the development of the methodology and statistical analysis. All authors helped draft and revise the manuscript and approved the final version.

\section{Conflicts of Interest}

None declared. 


\section{Multimedia Appendix 1}

Peer-reviewer report from Comite de Protection des Personnes Sud est V. [DOCX File, 19 KB-Multimedia Appendix 1]

\section{References}

1. Salisbury C, Johnson L, Purdy S, Valderas JM, Montgomery AA. Epidemiology and impact of multimorbidity in primary care: a retrospective cohort study. Br J Gen Pract 2011 Jan;61(582):e12-e21 [FREE Full text] [doi: 10.3399/bjgp11X548929] [Medline: 21401985]

2. Le Pape A, Sermet C. CREDES. 1997. The polypathology of the elderly, what home care? [in French] URL: http://credes. $\underline{\mathrm{fr}}$

3. Vedel I, De Stampa M, Bergman H, Ankri J, Cassou B, Blanchard F, et al. Healthcare professionals and managers' participation in developing an intervention: a pre-intervention study in the elderly care context. Implement Sci 2009 Apr 21;4:21 [FREE Full text] [doi: 10.1186/1748-5908-4-21] [Medline: 19383132]

4. Wargon M, Coffre T, Hoang P. 317 Durée d'attente des personnes agées aux urgences et dans l'unité d'hospitalisation des urgences. Journal Européen des Urgences 2004 Mar;17:119-120. [doi: 10.1016/s0993-9857(04)97305-0]

5. Creditor MC. Hazards of hospitalization of the elderly. Ann Intern Med 1993 Feb 01;118(3):219-223. [doi: 10.7326/0003-4819-118-3-199302010-00011] [Medline: 8417639]

6. Hoenig HM, Rubenstein LZ. Hospital-associated deconditioning and dysfunction. J Am Geriatr Soc 1991 Feb;39(2):220-222. [doi: 10.1111/j.1532-5415.1991.tb01632.x] [Medline: 1991956]

7. Neouze A, Dechartres A, Legrain S, Raynaud-Simon A, Gaubert-Dahan M, Bonnet-Zamponi D. Hospitalization of elderly in an acute-care geriatric department [in French]. Geriatr Psychol Neuropsychiatr Vieil 2012 Jun;10(2):143-150. [doi: 10.1684/pnv.2012.0350] [Medline: 22713842]

8. Mazière S, Lanièce I, Hadri N, Bioteau C, Millet C, Couturier P, et al. Predictors of functional decline of older persons after an hospitalisation in an acute care for elder unit: importance of recent functional evolution [in French]. Presse Med 2011 Feb;40(2):e101-e110. [doi: 10.1016/j.lpm.2010.05.023] [Medline: 21074350]

9. McCusker J, Bellavance F, Cardin S, Trépanier S, Verdon J, Ardman O. Detection of older people at increased risk of adverse health outcomes after an emergency visit: the ISAR screening tool. J Am Geriatr Soc 1999 Oct;47(10):1229-1237. [doi: 10.1111/j.1532-5415.1999.tb05204.x] [Medline: 10522957]

10. McCusker J, Verdon J, Tousignant P, de Courval LP, Dendukuri N, Belzile E. Rapid emergency department intervention for older people reduces risk of functional decline: results of a multicenter randomized trial. J Am Geriatr Soc 2001 Oct;49(10):1272-1281. [doi: 10.1046/j.1532-5415.2001.49254.x] [Medline: 11890484]

11. Rothschild JM, Bates DW, Leape LL. Preventable medical injuries in older patients. Arch Intern Med 2000 Oct 09;160(18):2717-2728. [doi: 10.1001/archinte.160.18.2717] [Medline: 11025781]

12. Ramanath R, Hendra TJ. How safe are our hospitals? Age Ageing 2008 May;37(3):243-245. [doi: 10.1093/ageing/afn087] [Medline: 18456788 ]

13. Covinsky KE, Palmer RM, Fortinsky RH, Counsell SR, Stewart AL, Kresevic D, et al. Loss of independence in activities of daily living in older adults hospitalized with medical illnesses: increased vulnerability with age. J Am Geriatr Soc 2003 Apr;51(4):451-458. [doi: 10.1046/j.1532-5415.2003.51152.x] [Medline: 12657063]

14. Jeandel C, Vigouroux P. Huit recommandations pour adapter la prise en charge des personnes âgées en établissement de santé. Cah Année Gerontol 2015 May 20;7(2):78-86. [doi: 10.1007/s12612-015-0451-9]

15. Haut conseil pour l'Avenir de l'Assurance maladie. 2011 Jun 23. Rapport "Assurance maladie et perte d'autonomie" URL: https://www.securite-sociale.fr/home/hcaam/zone-main-content/rapports-et-avis-1/rapport-assurance-maladie-et-per.html

16. Salles N, Diallo L, Videau M, Floccia M, Rainfray M. Does a hotline for general practitioners improve the care of older frail patients? A pilot study. Eur Geriatr Med 2013 Sep;4:S171-S172. [doi: 10.1016/j.eurger.2013.07.574]

17. Livre blanc fragilité. 2015. URL: http://www.medcomip.fr/--82/tg-formations/fragilite/livre-blanc-fragilite-2015.pdf [accessed 2019-03-11]

18. Charlson ME, Pompei P, Ales KL, MacKenzie CR. A new method of classifying prognostic comorbidity in longitudinal studies: development and validation. J Chronic Dis 1987;40(5):373-383. [doi: 10.1016/0021-9681(87)90171-8] [Medline: $\underline{3558716}$ ]

19. Charlson M, Szatrowski TP, Peterson J, Gold J. Validation of a combined comorbidity index. J Clin Epidemiol 1994 Nov;47(11):1245-1251. [doi: 10.1016/0895-4356(94)90129-5] [Medline: 7722560 ]

20. Quan H, Li B, Couris CM, Fushimi K, Graham P, Hider P, et al. Updating and validating the Charlson comorbidity index and score for risk adjustment in hospital discharge abstracts using data from 6 countries. Am J Epidemiol 2011 Mar 15;173(6):676-682. [doi: 10.1093/aje/kwq433] [Medline: 21330339]

21. Katz S, Ford AB, Moskowitz RW, Jackson BA, Jaffe MW. Studies of illness in the aged. The Index of ADL: a standardized measure of biological and psychosocial function. JAMA 1963 Sep 21;185:914-919. [doi: $\underline{10.1001 / j a m a .1963 .03060120024016}$ ] [Medline: 14044222] 
22. Lawton MP, Brody EM. Assessment of older people: self-maintaining and instrumental activities of daily living. Gerontologist 1969;9(3):179-186. [Medline: $\underline{\text { 5349366] }}$

23. Gluhm S, Goldstein J, Loc K, Colt A, Liew CV, Corey-Bloom J. Cognitive performance on the mini-mental state examination and the montreal cognitive assessment across the healthy adult lifespan. Cogn Behav Neurol 2013 Mar;26(1):1-5 [FREE Full text] [doi: 10.1097/WNN.0b013e31828b7d26] [Medline: 23538566]

24. Alais M. Admissions appropriées et inappropriées des personnes âgées aux urgences: impact d'une nouvelle diffusion du numéro de régulation gériatrique auprès des médecins généralistes de la Haute-Vienne [thesis]. Limoges, France: Université de Limoges; 2017. URL: http://aurore.unilim.fr/ori-oai-search/notice/view/unilim-ori-78277

25. Maréchal F, Kim B, Castel-Kremer E, Comte B. Évaluation de la ligne unique et directe d'appel teléphonique en gériatrie (ELUDAT G): une étude qualitative. NPG Neurologie - Psychiatrie - Gériatrie 2015 Dec;15(90):316-322 [FREE Full text] [doi: 10.1016/j.npg.2015.07.003]

26. Bailly A. Inte're^t d'une ligne te'le'phonique directe (Hotline) destine'e aux médecins pour limiter le passage aux urgences des personnes a^ge’s: analyse de 198 appels [thesis]. Saint-Étienne, France: Université Jean Monnet; 2014. URL: https:/ /www.worldcat.org/search?q=no\%3A892733117

27. Dijon J, Sarazin M, Augusto V, Franck T, Gonthier R, Célarier T. Comparison of two hospitalization modes in geriatrics either directly via a hotline or after an emergency unit admission. Geriatr Psychol Neuropsychiatr Vieil 2018 Sep 01;16(3):255-262. [doi: 10.1684/pnv.2018.0743] [Medline: $\underline{\text { 30168433] }}$

\title{
Abbreviations \\ ADL: activities of daily living \\ ED: emergency department \\ GP: general practitioner
}

\author{
Edited by G Eysenbach; submitted 09.07.19; peer-reviewed by C Showell, C McGregor; comments to author 15.10.19; revised version \\ received 28.10.19; accepted 29.10.19; published 13.02 .20 \\ Please cite as: \\ Martinez L, Lacour N, Gonthier R, Bonnefoy M, Goethals L, Annweiler C, Salles N, Jomard N, Bohatier J, Tardy M, Ojardias E, \\ Jugand R, Bongué B, Celarier T \\ Impact of Geriatric Hotlines on Health Care Pathways and Health Status in Patients Aged 75 Years and Older: Protocol for a French \\ Multicenter Observational Study \\ JMIR Res Protoc 2020;9(2):e15423 \\ URL: http://www.researchprotocols.org/2020/2/e15423/ \\ doi: $10.2196 / 15423$ \\ PMID: $\underline{32053116}$
}

CLaure Martinez, Noémie Lacour, Régis Gonthier, Marc Bonnefoy, Luc Goethals, Cedric Annweiler, Nathalie Salles, Nathalie Jomard, Jérôme Bohatier, Magali Tardy, Etienne Ojardias, Romain Jugand, Bienvenu Bongué, Thomas Celarier. Originally published in JMIR Research Protocols (http://www.researchprotocols.org), 13.02.2020. This is an open-access article distributed under the terms of the Creative Commons Attribution License (https://creativecommons.org/licenses/by/4.0/), which permits unrestricted use, distribution, and reproduction in any medium, provided the original work, first published in JMIR Research Protocols, is properly cited. The complete bibliographic information, a link to the original publication on http://www.researchprotocols.org, as well as this copyright and license information must be included. 